\title{
History of canids in Chile and impacts on prey adaptations
}

\author{
Benjamín Silva ${ }^{1}$ and Meredith Root-Bernstein ${ }^{2}$ \\ ${ }^{1}$ Pontifical Catholic University of Chile \\ ${ }^{2} \mathrm{CNRS}$
}

May 3, 2021

\begin{abstract}
Artiodactyl prey species of Chile, especially guanacos (Lama guanicoe) are reported to be very susceptible to predation by pack hunting feral dogs. It has been previously suggested that guanacos and endemic South American deer may have evolved in the absence of pack-hunting cursorial predators. However, the paleoecology of canid presence in southern South America and Chile is unclear. Here, we review the literature on South American and Chilean canids, their distributions, ecologies and hunting behaviour. We consider both wild and domestic canids, including Canis familiaris breeds. We establish two known antipredator defense behaviours of guanacos: predator inspection of ambush predators, e.g. Puma concolor, and rushing at and kicking smaller cursorial predators, e.g. Lycalopex culpaeus. We propose that since the late Pleistocene extinction of hypercarnivorous group-hunting canids east of the Andes, there were no native species creating group-hunting predation pressures on guanacos. Endemic deer of Chile may have never experienced group hunting selection pressure from native predators. Even hunting dogs (or other canids) used by indigenous groups in the far north and extreme south of Chile (and presumably the center as well) appear to have been used primarily within ambush hunting strategies. This may account for the susceptibility of guanacos and other prey species to feral dog attacks. We detail seven separate hypotheses that require further investigation in order to assess how best to respond to the threat posed by feral dogs to the conservation of native deer and camelids in Chile and other parts of South America.
\end{abstract}

History of canids in Chile and impacts on prey adaptations

Benjamín Silva Rochefort ${ }^{1}$ \& Meredith Root-Bernstein ${ }^{2,3,4}$

1. Facultad de Ciencias Biológicas, Universidad Católica de Chile, Santiago, Chile

2. Center of Applied Ecology and Sustainability, Santiago, Chile

3. Institute of Ecology and Biodiversity, Santiago, Chile

4. UMR CESCO, CNRS, Musée National d'Histoire Naturelle, Paris, France

\begin{abstract}
Artiodactyl prey species of Chile, especially guanacos (Lama guanicoe) are reported to be very susceptible to predation by pack hunting feral dogs. It has been previously suggested that guanacos and endemic South American deer may have evolved in the absence of pack-hunting cursorial predators. However, the paleoecology of canid presence in southern South America and Chile is unclear. Here, we review the literature on South American and Chilean canids, their distributions, ecologies and hunting behaviour. We consider both wild and domestic canids, including Canis familiaris breeds. We establish two known antipredator defense behaviours of guanacos: predator inspection of ambush predators, e.g. Puma concolor, and rushing at and kicking smaller cursorial predators, e.g. Lycalopex culpaeus. We propose that since the late Pleistocene extinction of hypercarnivorous group-hunting canids east of the Andes, there were no native species creating group-hunting predation pressures on guanacos. Endemic deer of Chile may have never experienced group hunting selection pressure from native predators. Even hunting dogs (or other canids) used by indigenous
\end{abstract}


groups in the far north and extreme south of Chile (and presumably the center as well) appear to have been used primarily within ambush hunting strategies. This may account for the susceptibility of guanacos and other prey species to feral dog attacks. We detail seven separate hypotheses that require further investigation in order to assess how best to respond to the threat posed by feral dogs to the conservation of native deer and camelids in Chile and other parts of South America.

Keywords: anti-predator defense; prehispanic dogs; cursorial; ambush; hunting; ethnography; evolution of prey behavior; predation strategy

\section{Introduction}

The damage to biodiversity caused by feral dogs (Canis familiaris) is well-established globally. Young et al. (2011), in a global review of feral dog impacts, show that the negative effects of $C$. familiaris on native species is widespread. Feral dogs are a serious problem for conservation, mainly because of their predation on native species, transmission of diseases, and competition with other predators, which may destabilize ecosystems (Ritchie et al. 2014; Hughes \& Macdonald 2013). For example, on the Galapagos Islands a significant decline in marine iguanas (Amblyrhinchus cristatus) resulted from the establishment of dogs on the island (Kruuk \& Snell 1981). Feral and freely ranging dogs in Brazilian protected areas displace native predators, spread diseases, and predate small and medium sized wildlife (Lessa et al. 2016). South America is a hotspot of C. familiaris negative impacts on threatened species (Doherty et al. 2017). Why exactly are dogs such a destabilizing conservation threat in South America in particular? Geist (1998) partly addressed one angle of this question when he concluded that the South American deer are not adapted to cursorial predators like dogs, and that deer traits like body size, locomotion, and reproductive investment, imply that there must have been only ambush predators present during the radiation of the South American deer species. In this paper, we re-examine and extend this hypothesis, to ask whether it can explain why deer and also camelids of South America are so vulnerable to feral dogs. We look more completely at all the evidence for the hunting strategies of prehistoric predators as well as domesticated canids associated with Precolumbian human presence. We focus on the case of Chile, and we end our review by evaluating the state of knowledge and suggesting hypotheses that need to be researched in order to better understand how the evolution and ecology of predator-prey interactions affect possible responses to the conservation challenge posed by feral dogs.

In Chile, feral dogs represent economic as well as environmental damage. C. familiaris is estimated to cause 57,000 sheep deaths annually (Bonacic \& Muñoz 2014), although it should be noted that this includes deaths caused by both feral and domestic dogs allowed to freely roam agricultural areas. Both feral and freely ranging human-dependent dogs cause significant reductions in the populations of threatened species in Chile. Freely ranging dogs that are poorly fed are more likely to prey on and harass wildlife (Silva-Rodríguez \& Sieving 2011). Rural dogs are interference competitors with the native fox Lycalopex griseus (Silva-Rodríguez et al. 2010), eat the eggs of migratory birds that nest in Chile (Shuttler et al. 2009), and predate on native deer species, including pudu Pudu puda (Silva-Rodríguez et al. 2009; Silva-Rodríguez \& Sieving 2012), and huemul Hippocamelus bisulcus (Flueck \& Smith-Flueck 2006; Corti et al. 2010). Reports from Peru (Barrio 2007) state that fawns of taruka, Hippocamelus antisensis, a deer also found in northern Chile, may be killed by shepherd and feral dogs. The native camelids, principally guanaco (Lama guanicoe), are considered by experts (pers. comm. WCS Chile Grupo Núcleo Guanacos 2020) to be particularly susceptible to being killed by feral dogs, and dog presence is considered to be a factor preventing the conservation and reintroduction of Lama guanicoe in large parts of its historical range (Farías et al. 2010; González 2010). According to McLaren et al. (2018), vicuña (Vicugna vicugna), a high-altitude relative of the guanaco, are hunted and harassed by humans with dogs, but feral dogs primarily predate on young offspring. It should be noted that the extent of the threat to species posed by dogs in Chile is partly due to the lack of a legal or cultural basis for their control, lethal or otherwise.

However, there are also behavioural and evolutionary features of predators to consider when trying to under- 
stand why feral dogs present a large and difficult-to-control threat to Chilean wildlife. When understanding predation, there are two key factors to consider: the predator's niche, and its hunting strategy. In terms of their niches, in general most canids (Carnivora: Canidae) are omnivores that do not kill (but may scavenge) prey larger than themselves (Sheldon 1992). Small canids $<6 \mathrm{~kg}$ are solitary foragers, canids $6-13 \mathrm{~kg}$ are facultative cooperative foragers, and larger ones are obligate cooperative foragers (Sheldon 1992) likely to be specialized as carnivores, with some exceptions (Wang et a. 2004). Canids, like other predators, may use either cursorial (pursuit) or ambush strategies. In cursorial strategies, the predator relies on its running adaptations and stamina to exhaust the prey, and may lack specific killing tactics, rather relying on bringing the prey down by biting (Fox 1987; Sheldon 1992; González 2010). In ambush strategies, the predator stalks the prey, remaining undetected until it can pounce on or rush at the prey from a short distance; it may rely on specialized killing tactics (Fox 1987; Sheldon 1992). For example, puma (Puma concolor) are ambush predators that kill with a specialized crushing bite to the head (Sarno et al. 1999).

In turn, prey species have adaptations such as scanning for predators, alarm calls, escape tactics, group defence tactics, and so on, which may be suited for different predator body sizes, group sizes, and either pursuit or ambush predation strategies (see Caro et al. 2004). Essentially, to escape cursorial predators, prey need to outrun or lose them. By contrast, the advantage of ambush predators is their ability to take a targeted prey individual by surprise from a short distance. An effective defence against ambush predation is "predator inspection" which consists of staring at, approaching, surrounding and/or following the predator so that it cannot gain this advantage (FitzGibbon 1994 provides an excellent review). In a study of gazelle, FitzGibbon (1994) found that they were much more likely to inspect ambush than cursorial predators. Inspecting cursorial predators is likely to be risky and maladaptive, as by shortening the distance to the predator it may increase the chances of being overtaken.

In its feral state, C. familiaris hunts in packs using a cursorial strategy (Farías et al. 2010; Ritchie et al. 2014). Geist (1998) notes that all of the South American deer lack appropriate defenses against what he calls "culling" predators, by which he appears to mean a cursorial strategy where one or more predators picks out and runs down its prey. Geist notes that South American deer are "curious" which suggests they approach possible threats. They also respond too late to attacks, are saltatorial bounders rather than runners, and lack stamina (Geist 1998). It has also been suggested that guanaco lack adaptations to escape cursorial pack hunters (Root-Bernstein \& Svenning 2016). The guanaco demonstrates group vigilance and predator inspection, suitable for countering its main native predator, the puma ( $P$. concolor), which hunts by solitary ambush (Darwin 2015 [1839]; Marino \& Baldi 2008; pers. obs. MR-B). It is not entirely clear whether guanacos inspect dog packs, but González (2010) attributes high dog-caused mortality to guanacos' short bursts of fast flight, leaving them unable to outrun dogs with greater stamina. Oyama (2006) describes vicuña ( V. vicugna) in the Peruvian Andes as approaching possible threats such as dogs, and facing predators while giving an alarm call. Similarly to the case of guanaco, vicuñas' main predators, including puma and foxes, hide in the long grass and ambush them.

If South American deer and camelids lack appropriate defense behaviours, does this imply that this is an evolutionary problem - that they lack an adaptive trait? Although prey must respond differently and appropriately to different predators, this does not necessarily imply the evolution of completely independent responses to each predator. Lind and Cresswell (2005) make the valuable point that "antipredation behaviours are a composite of many behaviours that an animal can adjust..." (p. 945). Components of anti-predator behaviour can be lost under loss of predation pressure, but the presence of any kind of predator may be enough to retain a whole suite of antipredation behaviours for tens of thousands of years (Blumstein 2006). So, to assess the hypothesis that key native Chilean prey species - camelids and deer-lack evolutionary adaptations to cursorial group predation, we would need to establish that they never in the past experienced selection pressures in the form of cursorial group hunting predators. Thus we need to understand when cursorial group-hunting canids first appeared in the southern cone of South America, which is not entirely clear. We focus on canids simply because there are not, and have never been, any group-hunting or cursorial felids in South America. 
It is clear that European conquistadors brought domestic dogs to the Americas starting around 500 years ago. However, the history of canids in South America, and ecological and behavioural descriptions of any kinds of prehispanic South American canids, have not been synthesized in a way accessible to conservationists. Here, we review existing evidence for the presence of prehispanic canids and their behaviours and ecological roles, focusing on Chile and the southern cone of South America.

\section{Canids and their hunting ecology}

\section{South American canids}

Up to 16 extinct canids (Wang et al. 2004), depending on the criteria used for phylogenetic studies, inhabited South America since around 3 Mya. Canids originated in North America and spread first to Eurasia upon the formation of the Bering Strait in the late Miocene (7-8 Mya), where they radiated into multiple lineages. Later, at 3,5 Mya they also spread to South America, in the Great American Biotic Interchange (GABI), which however may have started as early as 20 Mya (see Bacon et al. 2015, O'Dea et al. 2016, and Jaramillo et al. 2017). The GABI led to the evolution of new canid species, of which at least 7 were hypercarnivores (Prevosti \& Forasiepi 2018). Hypercarnivores are those species with a diet composed of at least $70 \%$ meat (Holliday \& Steppan 2004), and so have unique ecological characteristics and requirements, distinct from other species of the group. Particularly in Canidae, hypercarnivores are large in size due to energetic constraints (Wang et al. 2004) and thus also very likely to be obligatory cooperative group hunters (Sheldon 1992). The South American ancient hypercarnivores came from 4 genera, Theriodictis, Protocyon, Speothos, and Canis, the latter having three species, C. gezi, C. nehringi, and C. dirus (the dire wolf, also found in North America, although it has been recently included by Perri et al. (2021) in the genus Aenocyon, according to molecular data) (Wang et al. 2004; Prevosti 2010). Members of these genera all went extinct at the end of the Pleistocene, except the bush dog (Speothos venaticus) which is a small, short-legged group-hunting carnivorous canid living near water in the tropics. The hypercarnivorous Pleistocene species, distributed as far south as Argentina (Prevosti 2018), would most likely have hunted megafauna. Protocyon troglodytes, a group-living cursorial predator, as well as the non-hypercarnivorous canids Dusicyon spp in Uruguay hunted camelids, giant sloths, and other large and medium sized prey (Prevosti et al. 2009). Dusicyon spp. went extinct much later than the hypercarnivores (see below).

The 13 contemporary South American canids are divided into two lineages (Perini et al. 2010), one of species similar to Old World foxes (genera Lycalopex, Atelocynus, and Cerdocyon), and the other of species similar to Old World wolves (Chrysocyon and Speothos ). Although it is unclear, some authors (see Austin et al. 2013; Slater et al. 2009) consider this last lineage to be related to the extinct genus Dusicyon mentioned previously.

\section{South American canids in Chile}

The only one of the now-extinct South American Pleistocene canids known to have had a distribution in Chile was Dusicyon avus, found in Chilean Patagonia and Tierra del Fuego, on the southern tip of Chile (e.g. Méndez et al. 2014; Prevosti et al. 2009). The genus Dusicyon, to which D. avus and D. australis (also known as the Falklands wolf) belonged, went extinct fairly recently, although the extinction process may have been initiated by reductions in its distribution begining in the Pleistocene (Prevosti et al. 2011; Austin et al. 2013; Prevosti et al. 2015). In spite of this, there have been reported sightings of D. avus by English explorers as late as 1870. There are also theories that Dusicyon spp. underwent selection or hybridized with European C. familiaris and thus became unrecognisable but not necessarily extinct (Borrero 2009). The English natural historian Charles Hamilton Smith wrote in 1839 that mainland Dusicyon spp. were tamed and used for hunting by South American tribes (quoted in Clutton-Brock 1977). D. australis, restricted to the Falklands Islands, and extinct by the 1880s, shows morphological traits typical of domesticated canids, such as a bulbous head and white patches on its pelage (Clutton-Brock 1977), all of which may be a consequence of a long interaction with humans. As humans arrived in the Americas at the end of the Pleistocene, and in southern Chile around 14.5 kya (Gómez-Carballa et al. 2018; Braje et al. 2020), this gives any Dusicyon 
-human relationship considerable potential historical depth.

The other South American Pleistocene canids, especially the hypercarnivorous species, are not known to have occurred in Chile (Carrasco O. 2009). Since the uplift of the Andes occurred around 14 Mya (Le Roux 2012), well before the GABI, it may have formed a barrier to their dispersal. Other Pleistocene carnivores, including Smilodon populator, Panthera onca and Arctotherium tarijense are, like D. avus, found only in the extreme south of Chilean Patagonia (Carrasco O., 2009) where large parts of the Andean cordillera are below $1000 \mathrm{~m}$ and thus less of a barrier to dispersal. Indirect evidence suggests that they also travelled further north into northern Patagonia at least (Labarca et al. 2014). Other large predators (P. concolor) were (and are still) found in central Chile (Nielsen et al. 2015). New evidence could change known distributions: part of a skeleton of a large canid has been found in the Pampa de Tamarugal (Region of Tarapacá), undated but conjectured to be from before the arrival of the conquistadors to Chile (C. Latorre pers. comm. 2018, N. Villavicencio pers. comm. 2020).

Currently, three native canids exist in Chile, all of the genus Lycalopex (L. culpaeus, L. griseus , and L. fulvipes ). These species are omnivores, consuming small prey (Iriarte 2007). They have also been reported to opportunistically hunt juvenile guanacos (Novaro et al. 2009) in the Karukinka National Reserve, in Tierra del Fuego, where there are no pumas and the population of guanacos is high. According to Novaro et al. (2009), culpeo foxes L. culpaeus are cursorial predators. Juvenile guanaco, though much larger than culpeo foxes, are recorded to have been chased by them in two cases, and in at least one case, the attacking fox was kicked by several adult guanacos (Guzmán 2009). Lycalopex culpaeus also prey on huemul (Hippocamelus bisulcus ) fawns (Corti et al. 2010). It is thus likely that Lycalopex can exert a cursorial hunting selection pressure on juvenile large prey species, but since juveniles are often protected by adults who may attack the fox, this may mitigate the selection pressure. Juvenile anti-predator responses might also be adaptations distinct from adult behaviors. Franklin \& Powel (1994) report that guanacos as well as llamas respond to coyotes by alerting to them, alarm calling, walking or running towards them, chasing them, kicking and stomping on them.

\section{South American dogs}

Though $C$. familiaris, which co-evolved along with humans in Eurasia, is found early in the archeological record of North America, probably as a result of Bering Strait crossings, they arrive much later in South America. Dogs are reported from 4,5 kya in Ecuador and the coast of Peru (Stahl 1984; Salomon and Stahl 2008; Stahl 2012), and up to 10 kya in other parts of the Americas (Allison et al. 1982; van Asch et al. 2013, Perri et al. 2018).

It seems most probable that any dog present in Chile arrived along migratory or trade routes from the Andes, with the earliest evidence of dogs in the form of artistic representations from cultures such as the Moche (1900 ya - 1300 ya) or the Chimú (1100 kya - 500 ya) (Vásquez Sánchez et al. 2009). Prates et al. (2010) hypothesize that the presence of dogs in South America was mainly related to complex societies, such as the Andean societies of Peru and Ecuador previously mentioned, and that their arrival in the Southern Cone is related to an increase in long-distance communication and trade by egalitarian hunter-gatherer societies of the Pampas and Patagonia. The authors come to these conclusions based on archaeological deposits in northern Argentina dating from around 1000 ya (around 500 years before the arrival of the Spanish), which accords with other archaeological evidence of early dog presence in southern Brazil (1600 ya, Guedes Milheira et al. 2017) and in Uruguay (undated remains, but found in multiple-use structures starting around 1000 ya, López Mazz et al. 2018).

Many morphotypes of dogs may have been present in South America at different times. Gilmore (1950) lists nine possible breeds of South American dogs, remarking that parallel selection pressures or morphological constraints resulted in a terrier-like dog (the Fuegian dog), a setter-like dog (the Ona dog), a foxhound/greyhound type dog (the Tehuelche dog), and another terrier-like dog (the Techichi dog), as well as hairless dogs. The Pre-Columbian origins of these possible breeds is unknown. Van Asch et al. (2013) confirmed the pre-Columbian origins of several formally recognised American breeds, including the Peru- 
vian perro sin pelo ("hairless dog"). Vásquez Sánchez et al. (2009) summarize many possible morphotypes of South American dogs, including a short-nosed dog from the Chicama valley, the medium-sized "helping dog", the "pet" dog with a long body and short limbs, the miniature dog similar to a chihuahua, the hairless dog, a short-haired dog, a Peruvian bulldog, a Peruvian sausage dog, a long-haired Incan dog, and the Chiribaya shepherd used to herd llamas. Vásquez Sánchez et al. (2009) also discuss dogs depicted on Moche pots, including a morphotype consisting of a small or medium-sized spotted dog with a bulbous head, which appears in a deer-hunting scene among other contexts. They speculate that this kind of dog might have been used to corner deer during hunting. Like the Peruvian pitbull (Cossios E. 2018), many morphotypes may have been bred locally for certain periods of time, but later allowed to outcross with other morphotypes.

It is unclear whether prehispanic dogs of South America would have formed significant feral populations, although large packs of feral dogs are reported by the $18^{\text {th }}$ century (Prevosti et al. 2015), and it is hypothesized that feral populations existed soon after the beginning of dog domestication in Eurasia (Boitiani \& Ciucci 1995). Dogs, when feral or free ranging, are omnivorous opportunists (Campos et al. 2007). Dogs that are fed by humans tend to predate much less on wild prey (Vanak \& Gompper 2009). This indicates that, if there were either feral or free-ranging dogs in South America before the arrival of the Europeans, the pressure against succeptible wildlife may have a reasonable historical depth, although maybe not enough to allow prey to evolve adequate anti-predator behaviours.

\section{South American dogs in Chile}

Chile can be grouped into three large cultural areas: the North, with Incan influence, the Central-South zone, dominated by the Mapuche peoples, and the Southern region, associated with coastal hunter-gatherer cultures, which includes Patagonia. We discuss South American dogs in Chile in the sequence of these three cultural areas from north to south. However, the evidence for prehispanic dogs in each zone is relatively weak.

In Arica (northern Chile), eight mummified dogs, dated to circa 1450- 500 ya, were found by Allison et al. (1982), belonging to the San Miguel, Inca, Cabuza, Alto Ramirez and Maitas Chiribaya phases and periods. These are terrier-like dogs $46-52 \mathrm{~cm}$ high, apparently similar in form to the Moche hunting dogs discussed by Vásquez Sánchez et al. (2009).

It is commonly held in Chile, as well as recorded by historians (Vial 2010) and the ethnographer Ricardo Latcham (1822) that the contemporary Mapuche indigenous people of the center-south of Chile previously had two words for one or more kinds of dogs that they had: thegua or tregua and munutru. Mapuche dogs may have been obtained from Argentinian Patagonia pre-Columbian populations (Prates et al. 2010), or from the Inca (Uribe \& Sánchez 2016). According to Latcham (1822, p. 62), munutru refers to a dog with long curly hair on its face, or any "small ugly dog", similar to what is today called a "quiltro ", usually translated as "mutt", (ibid p. 62), and is reported by contemporary Mapuche people to mean anything with an "ugly face" (Loncon, E. pers. comm. 2019), while tregua simply means "dog." Some contemporary dogs in areas of central Chile, where indigenous populations persisted for several centuries after colonization, are "small ugly dogs", with bulbous foreheads and eyes, and short floppy ears, but no curly hair (pers. obs. MR-B). Perhaps these resemble the munutru or another indigenous dog morphotype. However, no specimens of Mapuche dogs are known to us either in the present day nor the archeological record.

The case of Patagonia in the extreme south of Chile also does not have good biological evidence about dogs. Ethnohistorical records of the $19^{\text {th }}$ and $20^{\text {th }}$ Century (Coiazzi 1914) mention the presence of dogs in societies that had little or no contact with the Spanish or other colonists. Coiazzi documents the coexistence of $C$. familiaris with hunter-gatherer societies of southern Patagonia, in particular the Selk'nam (also known as Ona), who used dogs to hunt guanacos among other animals. Martin Gusinde, famous Selk'nam etnographer, also recognized the presence of, at least in some form, domesticated dogs in Selk'nam encampments. These dogs, described as loud, aggressive, and with a pointed snout (Gusinde 1951), were very appreciated by the natives for their loyalty and protection, and as Gusinde described "In each house there are at least four of these acrimonious and irreconcilable dogs". Gusinde also described Selk'nam using dogs to hunt gua- 
nacos, even apparently picking up and following a scent in packs, just like hunting scent hounds in the UK and other areas with a tradition in hunting (Gusinde, 1951). The initial Spanish colonization of Chile only extended to Chiloé, which does not rule out a European origin of Selk'nam dogs via long-distance trade, but also makes it plausible that these dogs had a previous origin in pre-Columbian trade networks or migrations. Coiazzi (1914) suggests that the Selk'nam dogs had displaced the populations of a native canid similar to a fox, though whether he means by competition (cf. Vanak \& Gompper 2009) or as a favoured domesticate is unclear. Carlos R. Gallardo (1910) also wrote about the relationship between Selk'nam people and domesticated, supposedly native, dogs, described as "Canis (Pseudalopex) lycoides", also described as an important part of guanaco hunting. These domesticated dogs are described thouroughly in his book "The Onas":

"The fuegian dog is a not very big, wild looking animal. Some of them retain such a striking similarity to their ancestors, one can easily mistake them for a big fox, but (...) There are some of yellowish grey colour, of clear and almost white background, and with dark tints from black to ashen yellow. They have a broad forehead, straight, pointy, and fairly large ears, the eyes are somewhat oblique, the snout is long and even pointy, the neck is short, and the legs are notable for having very developed membranes between the fingers. The tail is long, covered in also long hair that coats the rest of the body as well."

Some of this description can be seen in Figure 1, from the same book (Gallardo 1910). In this context and with such characteristics, the possibility of a native canid being domesticated in Tierra del Fuego by Selk'nam is certainly more plausible. In addition to this, the study by Petrigh and Fugassa (2013), in which they genetically identified a taxidermized canid belonging to native people of the area showed that this specimen was closely related or identical to L. culpaeus.

Other, native, domesticated canids

Mitchell (2017) proposes a theory to explain the slow dynamics of spread of C. familiaris in South America, including the Southern Cone and Chile, after its original arrival across the Bering Strait. He argues that the canids of South America were better adapted to local diseases such as leishmaniasis canina and distemper than C. familiaris, and acted as reservoirs and vectors that led to almost epidemic levels of these diseases in dog populations, limiting their adoption by native peoples. The Andes may also have acted as a barrier to dog migration into Chile. An alternative perspective is developed by Prates (2014), who argues that many societies may have failed to incorporate C. familiaris into their social practices and daily lives if other canids already played roles such as keeping watch, hunting, or companionship. Prates bases this hypothesis on the discovery of a $D$. avus skeleton at a funerary site of the "Loma de los Muertos" archeological deposit in Río Negro Province, on the southern half of Argentina, dated around 2000-3000 ya (Stahl 2012, 2013; Prates, 2010). This is most probably a deliberate burial. In the context of cosmological systems in many areas of South America in which taming of individual animals is a common practice and a fundamental part of their understanding of social relations between species (Stahl, 1984; Erikson, 2000), this suggests the hypothesis of possible taming of canids in many societies of the continent. It is thus not impossible to imagine that some sort of domestication or taming of native canids by Patagonian hunter-gatherers happened in Chile (Gusinde, 1951; Gallardo, 1910).

C. familiaris was thus not necessarily the only canid either tamed or domesticated by humans. However, further research would be necessary to determine what kinds of relationships may have existed between native canids and humans in Chile, and to what extent this domestication took place, as at present we do not have archeological nor paleontological data to support these hypotheses.

Hunting strategies of and with canids in the Southern Cone and their effects on prey adaptations

It is difficult, based on morphology alone, to deduce behavioural strategies, given the amount of inter- and intraspecific variation in canids ( Sillero-Zubiri \& Macdonald 2004). Paleontologists, however, have noted that morphological specializations can favour particular hunting strategies in contemporary canids and felids, and thus by analogy there may have been similar tradeoffs in extinct mammals (Andersson 2005). For example, limbs can be cursorially specialized, elongating in the course of evolution to allow a wider stride, or specialized 
to "supinate the forearm, and thus grapple prey" when pouncing on it (Andersson 2005 p. 57). The latter is a common strategy used by ambush predators like felids. When the prey cannot be effectively grappled with the forearms, bringing down large prey with the mouth is the alternative; this latter kill strategy favours pack hunting and is usually seen in cursorial hunting tactics. Nevertheless, Andersson (2005) highlights exceptions. For example, lions, which can grapple excellently, are group hunters (using an ambush strategy), while $S$. venaticus, the bush dog, has very poor cursorial adaptations but is a group hunting species that brings prey down by biting. Ecological conditions such as shrub cover, by creating physical constraints, can also affect hunting strategies (Thibault \& Ouellet 2005, Karanth \& Sunquist 2000; Fanshawe \& Fitzgibbon 1993). Group hunting may contribute flexibility to hunting. Fanshawe and Fitzgibbon (1993), for example, show that African wild dogs, Lycaon pictus, unlike solitary ambush predators, were equally successful in killing prey in different amounts of cover, and alone or in groups of different sizes. While pack-hunting cursorial species such as C. lupus typically "troll" for and "test" prey in a cursorial mode, they also have group hunting tactics that include ambushes (Fox 1987). Many contemporary canid species hunt small prey alone and large prey in packs (e.g. Canis lupus , C. latrans , C. adustus , S. venaticus ; Andersson 2005). All of this indicates that it is not possible to clearly delimit two hunting strategies, since predator behaviour will depend on multiple factors.

The variation in predator behaviour makes a difference to prey. When faced with ambush vs. cursorial predators, large prey animals alter their anti-predator behaviours, notably by being more vigilant in habitat types associated with stalking and ambushing predators (Makin et al. 2017). Preissner et al. (2007) conclude that predator identity, e.g. hunting strategy, matters to prey life-history tradeoffs.

D. avus was the only large Pleistocene canid found in Chile (Castillo, 2007). Prevosti et al. (2009) report that $D$. avus likely predated Lama spp. as well as other large and medium animals, although they also indicate that Lama spp. may often have been scavenged rather than killed (Prevosti \& Vizcaíno 2006; Prevosti \& Martin 2013). The extinct Dusicyon spp. are described as "large foxes" (e.g. Prevosti et al. 2009), a description that may suggest that they did not live or hunt in packs, although like large-fox-like coyotes (Canis latrans) they might have lived in packs but hunted alone or in pairs. Coyotes are cursorial predators adapted to hunting in the open plains and prairies of North America (Thibault \& Ouellet 2005). At least part of the distribution of Dusicyon was open plains, so it could have shared a similar hunting strategy. Yet, as for L. pictus (Fanshawe \& Fitzgibbon 1993), they might be equally successful with a lone-hunting cursorial strategy in areas with tree cover, at least for certain prey. The maned wolf, Chrysocyon brachyurus is also large (up to $23 \mathrm{~kg}$ ) (Sheldon 1992) and described as fox-like (Dietz 1985), and in some accounts a sister genus of Dusicyon spp (Austin, 2013). While it has never occurred in Chile to date (Torres et al. 2013), it would have coexisted with Lama spp., rheas (Rhea spp. ), and other prey species whose ranges included Chile during the Holocene. It can thus both suggest potential D. avus hunting strategies by analogy, and suggest the kinds of strategies species found in Chile would also have been adapted to. Maned wolves are opportunistic and flexible omnivores that eat a variety of plant parts, insects, small animals, and medium sized animals of a similar mass to its own, including armadillos, Pampas deer (Ozotoceros bezoarticus , 22-34 $\mathrm{kg}$ ) and Greater rheas (Rhea americana , 20-27 kg) (de Almeida Jácomo et al. 2004; Aragona \& Setz 2001). Maned wolves hunt alone, and usually at night (Sheldon 1992; de Melo et al. 2007). They are typically found in open woodlands (cerrado) and tropical grasslands. Neither Dietz (1985) nor Sheldon (1992) clarify their hunting strategy or behaviour, but the long legs might indicate a cursorial adaptation. Alternately, it might simply (or also) be an adaptation to survey prey over the high grasses of the tropical grasslands. However, it was considerably smaller than an adult guanaco (L. guanicoe), and thus is unlikely to have actively hunted adults if it hunted alone. Thus, as for the culpeo fox, or coyotes in the context of llamas, we might expect that adult guanacos may have been able to counter-attack lone-hunting maned wolves as well as D. avus .

The surviving Pleistocene Lycalopex spp. found in Chile, as reported above, anecdotally attack juvenile camelids and prey on entrapped adults. However presumably it is difficult for the lone-hunting Lycalopex spp. to bring down adult guanacos or native deer, due to their small size, and their lack of a group hunting strategy (cf. the equally small bush dogs, Speothos venaticus, which are only able to bring down deer by biting them in large packs (Biben 1982; Sheldon 1992)). Otherwise, Lycalopex spp. can prey on fawns of 
medium and large ungulates (Corti et al. 2010).

We cannot necessarily conclude that widely distributed species such as guanacos, which would have been exposed prehistorically to cursorial pack-hunting, had different anti-predator adaptations in the populations to the west and the east of the Andes. However, it is possible that with the only remaining pack-hunting species in South America being the bush dog in the Amazonian basin, prey in the Southern Cone like guanaco may have lost, since the Pleistocene extinctions of the hypercarnivorous species, adaptations specific to surviving group predation tactics, whether cursorial or ambush.

By contrast, domesticated dogs may have been incorporated into particular roles in hunting with humans. Lupo (2017) presents ethnographic evidence that of the many forms of hunting with dogs, most of them, under most circumstances, have no appreciable benefit for hunting success. She argues that dogs are least useful for large prey that need to be hunted by stealth, and often interfere in ambushes and traps, but can be useful for finding and flushing prey, and handling certain prey. Although a large increase in effectiveness of hunting (compared to hunting without dogs) is observed when dogs are introduced as novel predators to islands and used in packs in combination with guns, other factors such as colonialism and land-use change also simultaneously alter technologies, economic drivers, and environmental conditions, such that the role of dogs alone is unclear in driving hunting outcomes (Lupo 2017). We cannot assume that even if hunting with larger dog packs might be more effective, hunters would necessarily prefer this tactic, since hunter-gatherers and many agriculturalists do not purposefully maximize productivity (Sahlins 1974[2017]). Rather, the evidence from Lupo (2017) is more consistent with viewing dogs as part of the social group (see the discussion of taming, above), than as hunting tools. How, in fact, were dogs incorporated into hunting tactics in Chile and the Southern Cone?

The dogs of the northern Andean civilizations and the north of Chile are all rather small, but some of them may have been used to corner game. The munutru was reportedly also small. The dogs of the Selk'nam, which appear to be medium-sized and shaped like dingos (Alvarado et al. 2007), had roles including chasing down guanacos that ran off after being stalked and struck by an arrow, taking down guanacos that the hunters were ambushing, or helping chase guanacos towards an ambush site (Legoupil 2011). Belardi et al. (2017) describe early Holocene communal hunting strategies to the East of the Andes, in Patagonia, that involved one group of hunters driving guanacos towards another group lying in wait; later on, constructed blinds were used. Santiago \& Salemme (2016) report that in addition to using group ambush tactics such as those described above, Selk'nam men often hunted alone, and women sometimes hunted with dogs: they do not clarify whether this was by pursuit or stalking. Across the Americas and across the Holocene, communal hunting driving large prey towards ambushes, opportunistic hunting of large animals mired in natural "traps" such as bogs and tar pits, and building traps including nets, are among the many tactics thought to have been used, with or without dogs (Davis \& Reeves 2014). The use of trapping technologies and tactics can be seen as a kind of displaced ambush, which like other forms of ambush require the prey to be highly alert and discerning about danger cues that try to blend into the environment (Gell 1996). We have not found clear evidence, before horses and cars, of pursuit followed by killing as a human hunting tactic for guanaco or other prey in Chile and the Southern Cone. Consequently, if indeed human hunting with dogs to the west of the Andes and the extreme south of the continent predated Europeans (as seems plausible), in itself this does not mean that guanacos or other prey were exposed to the same selective pressures as pack-hunting cursorial feral dogs pose today.

\section{Conclusions}

Why are the key large and medium prey species of Chile - camelids and deer - apparently unadapted to cursorial pack hunting by contemporary feral dogs? In summary, west of the Andes (within Chile) there is no clear evidence of group-hunting species or cursorial specialists large enough to bring down adults of these species (with the possible exception of the very small pudu Pudu puda ). However, the guanaco in particular has had a range throughout the Southern Cone, and should have been exposed to Pleistocene pack-hunting 
species that would have used cursorial strategies. It is unclear evolutionarily speaking whether appropriate anti-predation strategies might have been found only in the guanaco populations exposed to these predation pressures East of the Andes. The biology and evolution of predation defense suggests that suites of different kinds of defense behaviours can be maintained as long as any kind of predators are present (Blumstein 2006). Since there have always been puma and foxes in Chile, we would thus expect the prey species to maintain the capacity for any anti-predator behaviours that they had had to evolve.

For guanacos with their wide distribution in particular we can thus outline three possible scenarios or hypotheses: (1) only certain guanaco lineages east of the Andes were adapted to group-hunting cursorial strategies, and these populations have gone extinct (or are isolated from the Chilean populations); (2) the entire species had these adaptations but have lost them with the extinction of the predators in question at the end of the Pleistocene, contrary to the implication of Blumstein (2006); (3) these adaptations are latent in all guanacos' repertoire of possible adaptative responses to predation but for some reason which remains unclear (see below) seem to be expressed inadequately in Chilean populations. As for deer species and other camelids of Chile, these species have smaller ranges largely restricted to the Andes and the west of the Andes, so their prehistoric exposure to group-hunting cursorial strategies of predators east of the Andes is less clear, but possibly null.

However, these hypotheses are complicated by also considering the factor of indigenous people's PreColumbian hunting strategies involving domesticated canids, whether dogs or other species. It is probable that human hunters throughout the Southern Cone including Chile used dogs to assist in hunting well before the arrival of Europeans. These strategies were probably, given historical and comparative ethnographic evidence, primarily ambush strategies, although we cannot totally rule out cursorial-type strategies since group hunting in canids (and in humans) is usually quite flexible in form. So, we suggest two further hypotheses: (4) Pre-Columbian indigenous hunters also had an advantage in killing prey with canids similar to what is currently observed in canid hunting in Chile today, and for some reason prey species largely did not adapt to this group-hunting attack strategy perhaps due to lack of historical depth or continuity of the practices, or a continually changing habitat structure under human influences (which would affect predation strategies and success rates); (5) prey species did adapt to the group-hunting human-dog strategy, but only to the dominant ambush strategies, which is why they remain vulnerable to cursorial attacks. Again, it is not totally clear from the biology of adaptation to predation whether these two anti-predation strategies can be neatly separated in this way, since most examples of flexible prey anti-predation adaptations come from prey exposed to both ambush and cursorial strategies. This is an implicit sub-hypothesis that requires further research.

Although the logic of Geist (1998) suggesting a lack of cursorial predators is persuasive to explain deer adaptations, when also considering camelids, and when carefully looking at the evidence, the situation appears to be more complex than his argument accounts for.

We conclude that our state of knowledge about the biology and evolution of prey adaptations to different predation strategies, and the state of the base evidence for the existence of different canids in Chile and the rest of the Southern Cone of South America, are inadequate to address how the problem of feral dog predation on native species in these regions might be solved. For example, if native prey species really have no evolutionary background of exposure to group-hunting cursorial species, then only a natural process of selection could lead to its emergence. Whether it would be better, or more feasible, to expose native prey species to feral dogs in the hope of their eventual adaptation, or to eradicate feral dogs, is an open question. On the other hand, if guanacos in particular, and perhaps other species, have latent adaptations to group-hunting cursorial species, it is somewhat mysterious as to why they are so often killed by feral dogs. Here, there may be two more hypotheses to consider, which are quite different. (6) It could be the case that the rate of feral dog hunting success is not exceptionally high compared to "natural" predation, but is problematized due to its seeming unnaturalness. With current information this is difficult to assess. (7) It could be that camelids and deer need to learn socially (from parents or others) how to use certain anti-predator strategies of which they are behaviorally capable (Wiedenmayer 2009), but this possibility 
has been lost at some point in history due to loss of the behavioral expression among Chilean populations, either due to a Pleistocene predator extinction, or the local discontinuation of human hunting with dogs among relictual deer and camelid populations. In the latter case, training individuals to respond correctly to cursorial group attacks (Griffin et al. 2000) could be an approach to mitigate the problem by allowing social learning to spread.

Although we cannot offer any answers, we have clearly outlined the existing relevant knowledge and developed an array of hypotheses that should be tested, both to advance general knowledge of adaptations to predation, and to assist conservationists in designing appropriate interventions to conserve camelids and deer in South America and Chile in particular.

Acknowledgements

MR-B thanks WCS Chile for including her in the Grupo Núcleo Guanacos, which has been a useful forum to share information on threats to guanaco conservation.

Data accessibility statement

This is a qualitative review and analysis and there is no original or re-analysed data to share beyond the text found in this document.

\section{Bibliography}

Allison MJ, Focacci G, Santoro C (1982). The pre-Columbian dog from Arica, Chile. American Journal of Physical Anthropology, 59, 299-304.

Alvarado P.M., Odone, C., Maturana F.D., Fiore, D. (2007). Fueginos: fotografías siglos XIX y XX; imaginarios del mundo. Santiago de Chile, Pehuén, 301 p.

and the Antarctic Peninsula. Part 2: continental conditions. Sediment. Geol.

Andersson, K. (2005). Were there pack-hunting canids in the Tertiary, and how can we know?. Paleobiology, 31(1), 56-72.

Aragona, M., \& Setz, E. Z. F. (2001). Diet of the maned wolf, Chrysocyon brachyurus (Mammalia: Canidae), during wet and dry seasons at Ibitipoca State Park, Brazil. Journal of Zoology, 254(1), 131-136.

Austin JJ, Soubrier J , Prevosti FJ, Prates L, Trejo V, Mena F, Cooper A (2013). The origins of the enigmatic Falkland Islands wolf. Nature Communications, 4, 1552-1557.

Bacon, C. D., Silvestro, D., Jaramillo, C., Smith, B. T., Chakrabarty, P., \& Antonelli, A. (2015). Biological evidence supports an early and complex emergence of the Isthmus of Panama. Proceedings of the National Academy of Sciences, 112(19), 6110-6115.

Barrio, J. (2007). Análisis de viabilidad poblacional de la Taruka Hippocamelus antisensis (D’Órbigny, 1834)(Cervidae) en el sur del Perú. Revista Peruana de Biología, 14(2), 193-200.

Belardi, J. B., Marina, F. C., Madrid, P., Barrientos, G., \& Campan, P. (2017). Late Holocene guanaco hunting grounds in southern Patagonia: blinds, tactics and differential landscape use. Antiquity, 91 (357), 718-731.

Biben, M. (1982). Urine-marking during agonistic encounters in the bush dog (Speothos venaticus). Zoo biology, 1(4), 359-362.

Blumstein, D. T. (2006). The multipredator hypothesis and the evolutionary persistence of antipredator behavior. Ethology 112, 209-217.

Boitani, L., \& Ciucci, P. (1995). Comparative social ecology of feral dogs and wolves. Ethology Ecology \& Evolution, 7(1), 49-72. 
Bonacic C, y Munoz A (2014) El nuevo problema para la ganaderia, Revista Agronomia y Forestal UC, Volumen 49 (16), p.16-19.

Borrero, L.A. 2009. The elusive evidence: The archeological record of the South American extinct megafauna. In G. Haynes (ed.), American Megafaunal Extinctions at the End of the Pleistocene, 145-168. Springer Science.

Braje, T. J., Erlandson, J. M., Rick, T. C., Davis, L., Dillehay, T., Fedje, D. W., .. \& \& Pitblado, B. (2020). Fladmark+ 40: What Have We Learned about a Potential Pacific Coast Peopling of the Americas?. American Antiquity, 85(1), 1-21.

Campos, C. B., Esteves, C. F., Ferraz, K. M. P. M. B., Crawshaw Jr, P. G., \& Verdade, L. M. (2007). Diet of free-ranging cats and dogs in a suburban and rural environment, south-eastern Brazil. Journal of Zoology, 273(1), 14-20.

Caro, T. M., Graham, C. M., Stoner, C. J., \& Vargas, J. K. (2004). Adaptive significance of antipredator behaviour in artiodactyls. Animal behaviour, 67(2), 205-228.

Carrasco O., G. (2009). Mamiferos fosiles de Chile. Santiago, Chile, Instituto de Ecologia y Biodiversidad.

Castillo, J. (2007). Megabestias en Chile y otros vertebrados del Cenozoico. Mago Editores

Clutton-Brock, J. (1977). Man-made dogs. Science, 197(4311), 1340-1342.

Coiazzi, A. (1914). Los indios del archipielago fueguino. En Aborigenes fueguinios (81-102). Editorial Andujar.

Corti, P., Wittmer, H. U., \& Festa-Bianchet, M. (2010). Dynamics of a small population of endangered huemul deer (Hippocamelus bisulcus) in Chilean Patagonia. Journal of Mammalogy, 91 (3), 690-697.

Cossios E., D. (2018). El Pitbull Peruano: una raza canina extinguida. Revista de Investigaciones Veterinarias del Peru, 29(1), 362-367.

Darwin, C., 2015. It Was Snowing Butterflies. Penguin Classics, London, 1839

Davis, L.B., \& Reeves, B.O.K. 2014. Hunters of the recent past. London, Routledge Library Editions: Archaeology.

de Almeida Jacomo, A. T., Silveira, L., \& Diniz-Filho, J. A. F. (2004). Niche separation between the maned wolf (Chrysocyon brachyurus), the crab-eating fox (Dusicyon thous) and the hoary fox (Dusicyon vetulus) in central Brazil. Journal of Zoology, 262(1), 99-106.

de Melo, L. B., Sabato, M. L., Magni, E. V., Young, R. J., \& Coelho, C. M. (2007). Secret lives of maned wolves (Chrysocyon brachyurus Illiger 1815): as revealed by GPS tracking collars. Journal of Zoology, 271(1), $27-36$.

Dietz, J. (1985). Chrysocyon brachyurus. Mammalian Species,(234), 1-4.

Doherty, T. S., Dickman, C. R., Glen, A. S., Newsome, T. M., Nimmo, D. G., Ritchie, E. G., .. \& \& Wirsing, A. J. (2017). The global impacts of domestic dogs on threatened vertebrates. Biological conservation, 210, 56-59.

Erikson, P. 2000. The social significance of pet-keeping among Amazonian Indians. p. 7-26. In eds. Anthony L. Podberscek, Elizabeth S. Paul, James A. Serpell, Companion animals and us: Exploring the relationships between people and pets, Cambridge: Cambridge University Press.

Fanshawe, J. H., \& Fitzgibbon, C. D. (1993). Factors influencing the hunting success of an African wild dog pack. Animal behaviour, 45(3), 479-490.

Farias, A. A., Svensson, G. L., \& Jaksic, F. M. (2010). Ataque de perros. Plan Nacional de Conservacion de Guanacos, Macrozona Norte y Centro. Santiago, Chile. 
FitzGibbon, C. D. (1994). The costs and benefits of predator inspection behaviour in Thomson's gazelles. Behavioral Ecology and Sociobiology, 34(2), 139-148.

Flueck, W. T., \& Smith-Flueck, J. M. (2006). Predicaments of endangered huemul deer, Hippocamelus bisulcus, in Argentina: a review. European Journal of Wildlife Research, 52(2), 69-80.

Fox, M.W. (1987). Behaviour of Wolves, Dogs and related canids. Malabar, Florida: Robert E. Krieger Publishing Company.

Franklin, W. L., Powell, K. J., \& Youngs, C. R. (1994). Guard llamas. Iowa State University University Extension.Griffin, A. S., Blumstein, D. T. \& Evans, C. S. 2000: Training captive-bred or translocated animals to avoid predators. Conserv. Biol. 14, 1317-1326.

Gallardo, Carlos R. Los onas: Tierra del Fuego. Buenos Aires: Cabaut y Cia, Editores,1910

Geist, V. (1998). Deer of the world: their evolution, behaviour, and ecology. Mechanicsburg, PA, USA: Stackpole books.

Gell, A. 1996. Vogel's Net: Traps as Artworks and Artworks as Traps. Journal of Material Culture 1, 15-38.

Gilmore, R. M. (1950). Fauna and ethnozoology of South America (pp. 345-464). US Government Printing Office.

Gomez-Carballa, A., Pardo-Seco, J., Brandini, S., Achilli, A., Perego, U. A., Coble, M. D., ... \& Torroni, A. (2018). The peopling of South America and the trans-Andean gene flow of the first settlers. Genome research, 28(6), 767-779.

Gonzalez, B.A. 2010. Que problemas de conservacion tienen las poblaciones de guanaco en Chile? Ambiente Forestal, 5(9), 28-38.

Griffin, A. S., Blumstein, D. T., \& Evans, C. S. (2000). Training captive-bred or translocated animals to avoid predators. Conservation biology, $14(5), 1317-1326$.

Guedes Milheira R, Loponte DM, Garcia Esponda C, Acosta A, Ulguim P (2017). The First Record of a PreColumbian Domestic Dog (Canis lupus familiaris) in Brazil. International Journal of Osteoarchaeology, 27(3), p. 488-494. https://doi.org/10.1002/oa.2546

Gusinde, M. (1951) Fueguinos Escuela de Estudios Hispano-Americanos, Consejo de Superior de Investigaciones Cientificas.

Gusinde, M. (1951). Hombres primitivos en la Tierra del Fuego: de investigador a companero de tribu (No. 63). Escuela de Estudios Hispano-Americanos, Consejo de Superior de Investigaciones Cientificas.

Guzman H., L. (2009). Zorros osados estan atacando a los guanacos en Tierra del Fuego, El Mercurio, $18 / 2 / 2009$.

Holliday, J. A., \& Steppan, S. J. (2004). Evolution of hypercarnivory: the effect of specialization on morphological and taxonomic diversity. Paleobiology, 30(1), 108-128.

Hughes, J., \& Macdonald, D. W. (2013). A review of the interactions between free-roaming domestic dogs and wildlife. Biological Conservation, 157, 341-351.

Iriarte, A. 2007. Mamiferos de Chile. Ediciones. Santiago, Chile. 236-244

Jaramillo, C., Montes, C., Cardona, A., Silvestro, D., Antonelli, A., \& Bacon, C. (2017). Comment (1) on "Formation of the Isthmus of Panama" by O'Dea et al. Science Advances, 3(6), e1602321. doi: 10.1126/sciadv.1602321

Karanth, K. U., \& Sunquist, M. E. (2000). Behavioural correlates of predation by tiger (Panthera tigris), leopard (Panthera pardus) and dhole (Cuon alpinus) in Nagarahole, India. Journal of Zoology, 250(2), 255265. 
Kruuk H, Snell H (1981). Prey Selection by Feral Dogs from a Population of Marine Iguanas (Amblyrhynchus Cristatus). The Journal of Applied Ecology. 18, p.197-204. 10.2307/2402489.

Labarca, R., 2015. La Meso y Megafauna extinta del Pleistoceno de Chile. Publicacion Ocasional del Museo Natl. .Hist. Natl. Chile 63, 401e465.

Labarca, R., Recabarren, O. P., Canales-Brellenthin, P., \& Pino, M. (2014). The gomphotheres (proboscidea: Gomphotheriidae) from Pilauco site: Scavenging evidence in the Late Pleistocene of the Chilean Patagonia. Quaternary International, 352, 75-84.

Latcham, R.E. 1822. Los animales domesticos de la America precolumbina. Santiago, Chile: Cervantes.

Le Roux, J., 2012. A review of Tertiary climate changes in southern South America

Legoupil D., 2011 La chasse aux guanacos chez les Selk'nam de Terre de Feu : faible tracabilite des haltes temporaires et polyvalence du site d'abattage, in Bon Fr., Costamagno S., Valdeyron N. (dir.), Haltes de chasse en Prehistoire. Quelles realites archeologiques?, Actes du colloque international du 13 au 15 mai 2009, universite Toulouse II - Le Mirail, P@lethnologie, 3, 21-40.

Lessa, I., Guimaraes, T. C. S., de Godoy Bergallo, H., Cunha, A., \& Vieira, E. M. (2016). Domestic dogs in protected areas: a threat to Brazilian mammals?. Natureza \& Conservacao, 14(2), 46-56.

Lind, J., \& Cresswell, W. (2005). Determining the fitness consequences of antipredation behavior. Behavioral Ecology, 16(5), 945-956.

Lopez Mazz JM, Moreno F, Bracco R, Gonzalez R. (2018). Perros prehistoricos en el este de Uruguay: contextos e implicaciones culturales. Latin American Antiquity, 29(1), 64-78. https://doi.org/10.1017/laq.2017.48

Lupo, K. D. (2017). When and where do dogs improve hunting productivity? The empirical record and some implications for early Upper Paleolithic prey acquisition. Journal of Anthropological Archaeology, 47, $139-151$.

Makin, D. F., Chamaille-Jammes, S., \& Shrader, A. M. (2017). Herbivores employ a suite of antipredator behaviours to minimize risk from ambush and cursorial predators. Animal Behaviour, 127, 225-231.

Marino, A., \& Baldi, R. (2008). Vigilance patterns of territorial guanacos (Lama guanicoe): the role of reproductive interests and predation risk. Ethology, 114(4), 413-423.

McLaren, B. E., MacNearney, D., \& Siavichay, C. A. (2018). Livestock and the functional habitat of vicunas in Ecuador: a new puzzle. Ecosphere, 9(1).

Mendez, C., Barberena, R., Reyes, O., \& Nuevo Delaunay, A. (2014). Isotopic Ecology and Human Diets in the Forest-Steppe Ecotone, Aisen Region, Central-Western Patagonia, Chile. International Journal of Osteoarchaeology, 24(2), 187-201.

Mitchell P (2017). Disease: A Hitherto Unexplored Constraint on the Spread of Dogs (Canis lupus familiaris) in Pre-Columbian South America. Journal of World Prehistory, 30(4), 301-349. https://doi.org/10.1007/s10963-017-9111-x

Montecino-Latorre D, Martin WS (2018). Evidence supporting that human-subsidized free-ranging dogs are the main cause of animal losses in small-scale farms in Chile. W. Ambio. p. 111. https://doi.org/10.1007/s13280-018-1066-3.

Nielsen, C., Thompson, D., Kelly, M. \& Lopez-Gonzalez, C.A. 2015. Puma concolor (errata version published in 2016). The IUCN Red List of Threatened Species 2015

Novaro A, Moraga CA, Briceno C, Funes MC, Marino A (2009) First records of culpeo (Lycalopex culpaeus) attacks and cooperative defense by guanacos (Lama guanicoe). Mammalia 73:148-150. 
O'Dea, A., Lessios, H. A., Coates, A. G., Eytan, R. I., Restrepo-Moreno, S. A., Cione, A. L., ... Jackson, J. B. C. (2016). Formation of the Isthmus of Panama. Science Advances, 2(8), e1600883. https://doi.org/10.1126/sciadv.1600883

Oyama, S. 2006. Ecology and wildlife conservation of vicuna in Peruvian Andes. Geographical Reports of Tokyo Metropolitan University, 41, 27-44.

Perini, F. A., Russo, C. A. M., \& Schrago, C. G. (2010). The evolution of South American endemic canids: a history of rapid diversification and morphological parallelism. Journal of evolutionary biology, 23(2), 311-322.

Perri, A., Widga, C., Lawler, D., Martin, T., Loebel, T., Farnsworth, K., Kohn, L., Buenger, B. (2019). New evidence of the earliest domestic dogs in the Americas. American Antiquity, 84(1), 68-87. http: //doi.org/10.1017/aaq.2018.74

Perri, A.R., Mitchell, K.J., Mouton, A. et al. Dire wolves were the last of an ancient New World canid lineage. Nature (2021).

Petrigh, R. S., \& Fugassa, M. H. (2013). Molecular identification of a Fuegian dog belonging to the Fagnano Regional Museum ethnographic collection, Tierra del Fuego. Quaternary International, 317, 14-18.

Prates L, Di Prado, V, Mange E \& Serna A (2010). Sitio loma de los muertos: multiples ocupaciones sobre un medano del este de norpatagonia (argentina). Magallania (punta arenas), 38(1), 165-181.

Prates L, Prevosti FJ, Beron M (2010). First Records of Prehispanic Dogs in Southern South America (Pampa-Patagonia, Argentina). Current Anthropology, 51(2), 273-280.

Prates, L. (2014). Crossing the boundary between humans and animals: the extinct fox Dusicyon avus from a hunter-gatherer mortuary context in Patagonia (Argentina). Antiquity, 88(342), 1201.

Preisser, E. L., Orrock, J. L., \& Schmitz, O. J. (2007). Predator hunting mode and habitat domain alter nonconsumptive effects in predator-prey interactions. Ecology, 88(11), 2744-2751.

Prevosti FJ (2010). "Phylogeny of the large extinct South American Canids (Mammalia, Carnivora, Canidae) using a "total evidence" approach". Cladistics. 26 (5) p.456-481.

Prevosti FJ (2013). Constraining the time of extinction of the South American fox Dusicyon avus (Carnivora, Canidae) during the late Holocene. Quaternary International, 19(2), 1-19. https://doi.org/10.1111/j.10960031.2009.00298.x

Prevosti FJ, Forasiepi AM (2018). Evolution of South American mammalian predators during the Cenozoic: paleobiogeographic and paleoenvironmental contingencies. (Elsevier, Ed.). https://doi.org/10.1007/978-3319-03701-1

Prevosti F.J., M. Ubilla \& D. Perea (2009) Large extinct canids from the Pleistocene of Uruguay: systematic, biogeographic and paleoecological remarks, Historical Biology, 21:1-2, 79-89

Prevosti, F. J., \& Martin, F. M. (2013). Paleoecology of the mammalian predator guild of Southern Patagonia during the latest Pleistocene: ecomorphology, stable isotopes, and taphonomy. Quaternary International, 305, 74-84.

Prevosti, F. J., \& Vizcaino, S. F. (2006). Paleoecology of the large carnivore guild from the late Pleistocene of Argentina. Acta Palaeontologica Polonica, 51 (3).

Prevosti, F. J., Ramirez, M. A., Schiaffini, M., Martin, F., Udrizar Sauthier, D. E., Carrera, M., ... \& Pardinas, U. F. (2015). Extinctions in near time: new radiocarbon dates point to a very recent disappearance of the South American fox Dusicyon avus (Carnivora: Canidae). Biological Journal of the Linnean Society, 116(3), 704-720. 
Prevosti, F. J., Santiago, F., Prates, L., \& Salemme, M. (2011). Constraining the time of extinction of the South American fox Dusicyon avus (Carnivora, Canidae) during the late Holocene. Quaternary International, 245(2), 209-217.

Ritchie, E. G., Dickman, C. R., Letnic, M., Vanak, A. T., \& Gommper, M. (2014). Dogs as predators and trophic regulators. Free-ranging dogs and wildlife conservation, 55-68.

Root-Bernstein, M., \& Svenning, J. C. (2016). Prospects for rewilding with camelids. Journal of Arid Environments, 130, 54-61.

Sahlins, M. 1974[2017]. Stone Age Economics. London, Routledge Classics.

Salomon, I. B., \& Stahl, P. W. (2008). Un enterramiento canino en Real Alto: Implicaciones para el estudio del perro prehispanico en el Nuevo Mundo. Unpublished paper presented at the III Congreso Ecuatoriano de Antropologia y Arqueologia.

Santiago, F. C., \& Salemme, M. C. (2016). Guanaco hunting strategies in the northern plains of Tierra del Fuego, Argentina. Journal of Anthropological Archaeology, 43, 110-127.

Sarno, R. J., Clark, W. R., Bank, M. S., Prexl, W. S., Behl, M. J., Johnson, W. E., \& Franklin, W. L. (1999). Juvenile guanaco survival: management and conservation implications. Journal of Applied Ecology, 36(6), 937-945.

Schuttler, E., Klenke, R., McGehee, S., Rozzi, R., \& Jax, K. (2009). Vulnerability of ground-nesting waterbirds to predation by invasive American mink in the Cape Horn Biosphere Reserve, Chile. Biological Conservation, 142(7), 1450-1460.

Sepulveda MA, Singer RS, Silva-Rodriguez E, Stowhas P, Pelican K (2014) Domestic Dogs in Rural Communities around Protected Areas: Conservation Problem or Conflict Solution? PLoS ONE 9(1): e86152.

Sheldon, J.W. 1992. Wild dogs: The natural history of the nondomestic Canidae. San Diego, CA: Academic Press.

Sillero-Zubiri, C., \& Macdonald, D. W. (Eds.). (2004). The biology and conservation of wild canids. Oxford: Oxford University Press.

Silva-Rodriguez E.A., Ortega-Solis G.R. \& Jimenez J. E. (2010). Conservation and ecological implications of the use of space by chilla foxes and free-ranging dogs in a human-dominated landscape in southern Chile. Austral Ecology, 35(7), 765-777.

Silva-Rodriguez E. A. \& Sieving K. E. (2011). Influence of care of domestic carnivores on their predation on vertebrates. Conservation Biology, 25(4), 808-815.

Silva-Rodriguez, E. A., \& Sieving, K. E. (2012). Domestic dogs shape the landscape-scale distribution of a threatened forest ungulate. Biological Conservation, 150(1), 103-110.

Silva-Rodriguez, E. A., Verdugo, C., Aleuy, O. A., Sanderson, J. G., Ortega-Solis, G. R., Osorio-Zuniga, F., \& Gonzalez-Acuna, D. (2010). Evaluating mortality sources for the Vulnerable pudu Pudu puda in Chile: implications for the conservation of a threatened deer. Oryx, 44 (1), 97-103.

Slater, G. J., Thalmann, O., Leonard, J. A., Schweizer, R. M., Koepfli, K.-P., Pollinger, J. P., ... Wayne, R. K. (2009). Evolutionary history of the Falklands wolf. Current Biology, 19(20), R937R938. doi:10.1016/j.cub.2009.09.018

Stahl PW (1984). Tropical forest cosmology: The cultural context of the Early Valdivia occupations at Loma Alta. PhD thesis, University of Illinois at Urbana-Champaign.

Stahl, P. W. (2012). Interactions Between Humans and Endemic Canids in Holocene South America. Journal of Ethnobiology, 32(1), 108-127. 
Stahl, P. W. (2013). Early dogs and endemic south american canids of the spanish main. Journal of Anthropological Research, 69(4), 515-533.

Thibault, I., \& Ouellet, J. P. (2005). Hunting behaviour of eastern coyotes in relation to vegetation cover, snow conditions, and hare distribution. Ecoscience, 12(4), 466-475.

Torres, R., Jayat, J. P., \& Pacheco, S. (2013). Modelling potential impacts of climate change on the bioclimatic envelope and conservation of the Maned Wolf (Chrysocyon brachyurus). Mammalian Biology, 78(1), 41-49.

Uribe, M. \& Sanchez, R. 2016. Los incas en Chile. Aportes de la arqueologia chilena a la historia del Tawantinsuyo (ca. 1.400 a 1.536 anos d.C.). p 529-572 in Eds. F. Fallabella, M. Uribe, L. Sanhueza, C. Aldunate, \& J. Hidalgo. Prehistoria en Chile: Desde sus primeros habitantes hasta los Incas. Editorial Universitaria.

van Asch, B., Zhang, A. B., Oskarsson, M. C., Klutsch, C. F., Amorim, A., \& Savolainen, P. (2013). Pre-Columbian origins of Native American dog breeds, with only limited replacement by European dogs, confirmed by mtDNA analysis. Proceedings of the Royal Society B: Biological Sciences, 280(1766), 20131142.

Vanak, A. T., \& Gompper, M. E. (2009). Dogs Canis familiaris as carnivores: their role and function in intraguild competition. Mammal Review, 39(4), 265-283.

Vasquez Sanchez, V.F., Rosales Tham, T.E., \& Dorado, G. 2009. Morphotypes and breeds of dogs (Canis lupus familiaris L.) from the Moche period. Arqueobios 3(1): 20-33

Vial, G. (2010). Chile, cinco siglos de historia: desde los primeros pobladores prehispanicos, hasta el ano 2006.

Wang, X., Tedford, R. H., Van Valkenburgh, B., \& Wayne, R. K. (2004). Evolutionary history, molecular systematics, and evolutionary ecology of Canidae. Biology and conservation of wild canids (DW Macdonald and C. Sillero-Zubiri, eds.). Oxford University Press, Oxford, United Kingdom, 39-54.

Wiedenmayer, C. P. (2009). Plasticity of defensive behavior and fear in early development. Neuroscience $\mathcal{E}$ Biobehavioral Reviews, 33(3), 432-441.

Young JK, Olson KA, Reading RP, Amgalanbaatar S, Berger J (2011) Is Wildlife Going to the Dogs? Bioscience 61 (2). p. 125-132. 10.1525/bio.2011.61.2.7 


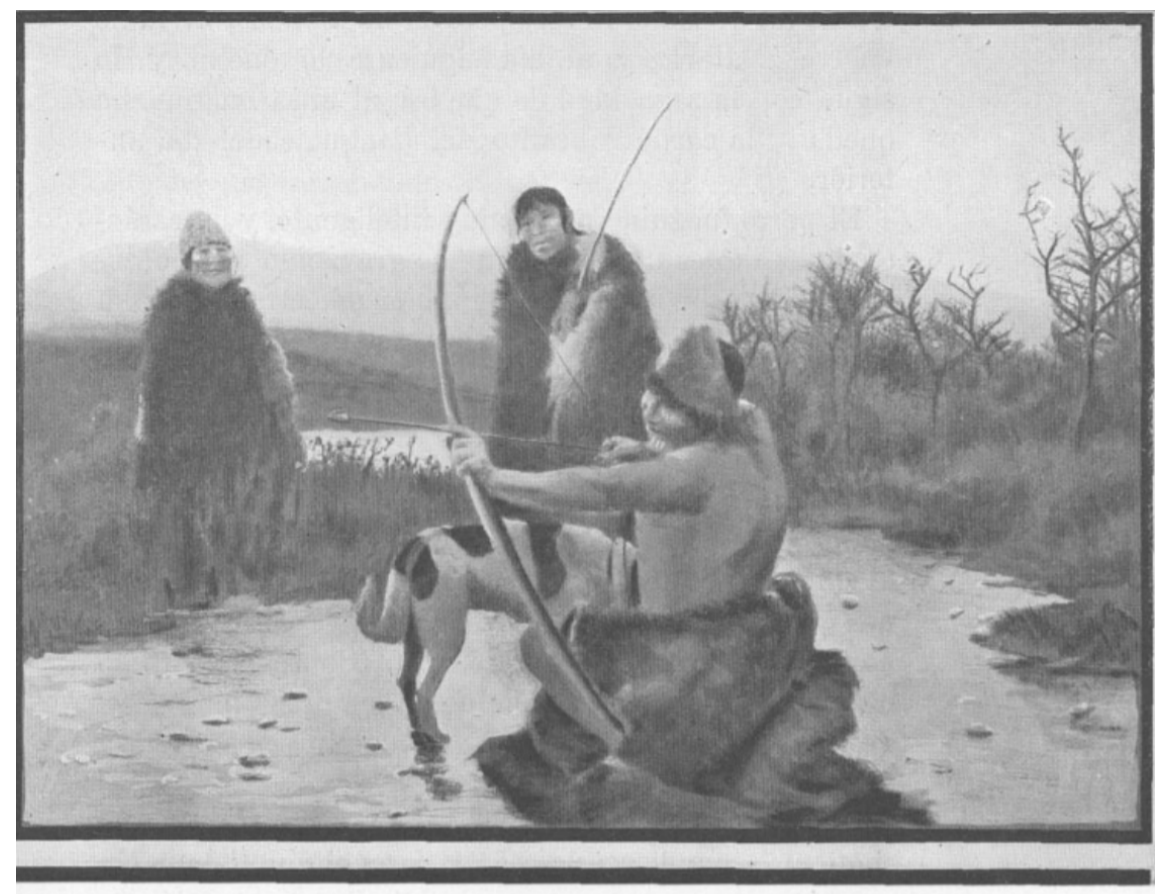

Educando al perro.

Figure 1. Reproduction of a drawing found in "The Onas" by Carlos Gallardo (1910) titled "Educating the dog" (Educando al perro ). Some characteristics mentioned in the text can be seen in the drawing of this Fueguian dog. The image is free of copyright (http://www.memoriachilena.gob.cl/602/w3-article-8403.html) 